\title{
Hearing Impairment in pseudoexfoliation syndrome
}

\author{
Sheldon Goudinho ${ }^{1}$, Renjini. R.I ${ }^{2}$, Jasmine Mary Jacob ${ }^{3, *}$ \\ ${ }^{1}$ Professor and HOD, ${ }^{2}$ Post Graduate, ${ }^{3}$ Professor, Dept. of Ophthalmology, Dr. Somervell Memorial CSI Medical College, \\ Karakonam, Kerala, India
}

*Corresponding Author:

Email: shelandjas@yahoo.com

\begin{abstract}
Aim: to compare the degree of sensorineural hearing loss in patients with and without pseudo exfoliation.

Materials and Methods: A comparative study design enrolling 44 patients each with and without pseudoexfoliation was employed. Pure tone audiometry was done to detect sensorineural hearing loss and to quantify the same according to WHO classification.

Results: $52.3 \%$ of patients in the group with pseudo exfoliation had mild sensorineural hearing loss, i.e., difficulty with faint speech.6.8\% had moderate sensorineural hearing loss.40.9\% had no significant hearing loss. In the group without pseudo exfoliation, $56.8 \%$ had no significant hearing loss while $29.5 \%$ had mild sensorineural hearing loss.13.6\% had moderate to moderately severe sensorineural hearing loss.

Conclusion: There is an increased incidence of hearing impairment in pseudo exfoliation syndrome though not statistically significant.
\end{abstract}

Keywords: Pseudoexfoliation, Sensorineural hearing loss.

\section{Introduction}

Pseudoexfoliation syndrome is a condition associated with deposition of dandruff-like material on the iris, cornea, anterior lens capsule, trabecular meshwork and lens Zonules. ${ }^{1-4,27,36,39}$ It is detected, most often, as an incidental finding in the Ophthalmology outpatient department. According to various cross sectional studies, the prevalence of pseudoexfoliation syndrome in South India ranges from $3.01 \%$ to $6 \%$ in the age group more than forty years. ${ }^{1-3}$ it has a much higher prevalence in the age group more than 60 years.

Research over the past two decades have proved that psuedoexfoliation occurs in different parts of the body like blood vessels, skin, meninges, visceral organs, etc. ${ }^{4-7}$ This indicates that psuedoexfoliation syndrome may indeed be one of the manifestations of a systemic disease. ${ }^{11-15}$

Eyes and ears are undoubtedly the most cardinal sense organs of the body. Pseudoexfoliation syndrome is a manifestation in the middle aged and elderly (usually more than forty years). The impact that any change in the vision or hearing ability could make in the quality of life of these patients cannot be understated. $^{16,17}$ Research done in different ethnic groups have shown an association between pseudoexfoliation syndrome and hearing loss. ${ }^{4-7}$ to our knowledge, only one such study has been conducted so far in India. ${ }^{7}$

Psuedoexfoliation syndrome is associated with a higher incidence of secondary glaucoma (psuedoexfoliation glaucoma). The poor pupillary mydriasis, weakness of lens Zonules, increased incidence of vitreous loss and risk of corneal endothelial decompensation make the visual outcome of ocular surgeries, especially cataract surgery in such patients' unpredictable. . $^{8-11,34,40}$

Embryologically, the tectorial and basilar membranes in the inner ear and the anterior segment structures of the eye are partly derived from the neuroectoderm. ${ }^{8,9}$ Possible accumulation of pseudoexfoliation material on these structures may lead to sensorineural hearing loss due to the dysfunction of the mechanoreceptors of the ear. Deposition of fibrillar pseudoexfoliation material in the vessel walls ${ }^{10}$ may suggest similar changes in the vasculature of the inner ear causing a decrease in nourishment of the inner ear and worsening of the metabolism in the striae vascularis, which may lead to sensorineural hearing loss. ${ }^{18-20}$

Keeping in mind the greater risk of visual deterioration in these patients due to glaucoma and cataract, it is important to detect any significant impairment in hearing as well so that early rehabilitation may be provided.

This study aims to compare the degree of sensorineural hearing loss between two groups of patients with and without pseudoexfoliation.

\section{Materials and Methods}

After obtaining ethical clearance from the institution (Dr. SMCSI Medical College, Karakonam), a comparative study was conducted between January 2015 to January 2017. 44 patients with and 44 patients without psuedoexfoliation (above forty years) were enrolled for the study. Exclusion criteria: history of congenital hearing loss, previous ear surgery, acute or chronic ear diseases, ear or head trauma, prolonged noise exposure, prolonged use of ototoxic drugs, vascular and systemic diseases that may be related to 
hearing loss (eg: uncontrolled hypertension), patients with conductive or mixed hearing loss, ocular conditions associated with hearing loss, patients with true exfoliation of lens capsule.

Full ophthalmic examination including Snellen's uncorrected and best corrected visual acuity, slit lamp biomicroscopy, gonioscopy (Shaffer), Goldmann applanation tonometry, dilated fundus examination with +90D noncontact lens was performed in all patients.

Otologic examination was performed to rule out external and middle ear anomalies. It included ear inspection, otoscopy, nasopharyngeal examination and tuning fork testing. Using pure tone audiometry, the hearing threshold (minimal intensity of perceptible sound) was calculated for every ear, using air and bone conduction, at the frequencies of 250, 500, 2000, 4000 and $8000 \mathrm{~Hz}$.
Based on pure tone audiogram, patients with conductive or mixed hearing loss were excluded. Calculation of mean hearing threshold (pure tone average) included the speech frequencies $500 \mathrm{~Hz}, 1000$ $\mathrm{Hz}$ and $2000 \mathrm{~Hz}^{23,26}$

Sensorineural hearing loss is characterised by no air-bone gap in audiometry. It is significant when mean hearing threshold (pure tone average) is above $25 \mathrm{~dB}$. WHO has classified the degree of sensorineural hearing loss on the basis of pure tone audiogram taking the average of the thresholds of hearing for frequencies of 500,1000 and $2000 \mathrm{~Hz}$ with reference to ISO:R.3891970(International Calibration of Audiometers). ${ }^{40-43}$

WHO classified the degree of impairment from sensorineural hearing loss as follows:

Table 1: WHO classification of the degree of impairment from sensorineural hearing los

\begin{tabular}{|l|c|c|}
\hline $\begin{array}{l}\text { Hearing threshold in } \\
\text { better ear(average of } \\
\mathbf{5 0 0 , 1 0 0 0} \text { and } 2000 \\
\text { dBz) in }\end{array}$ & $\begin{array}{c}\text { Degree of impairment } \\
\text { (WHO classification) }\end{array}$ & Ability to understand speech \\
\hline $0-25$ & Not significant & $\begin{array}{c}\text { No significant difficulty with faint } \\
\text { speech }\end{array}$ \\
\hline $26-40$ & Mild & Difficulty with faint speech \\
\hline $41-55$ & Moderate & $\begin{array}{c}\text { Frequent difficulty with normal } \\
\text { speech }\end{array}$ \\
\hline $56-70$ & Moderately severe & $\begin{array}{c}\text { Frequent difficulty even with loud } \\
\text { speech }\end{array}$ \\
\hline $71-91$ & Severe & $\begin{array}{c}\text { Can understand only shouted or } \\
\text { amplified speech }\end{array}$ \\
\hline Above 91 & Profound & $\begin{array}{c}\text { Usually cannot understand even } \\
\text { amplified speech }\end{array}$ \\
\hline
\end{tabular}

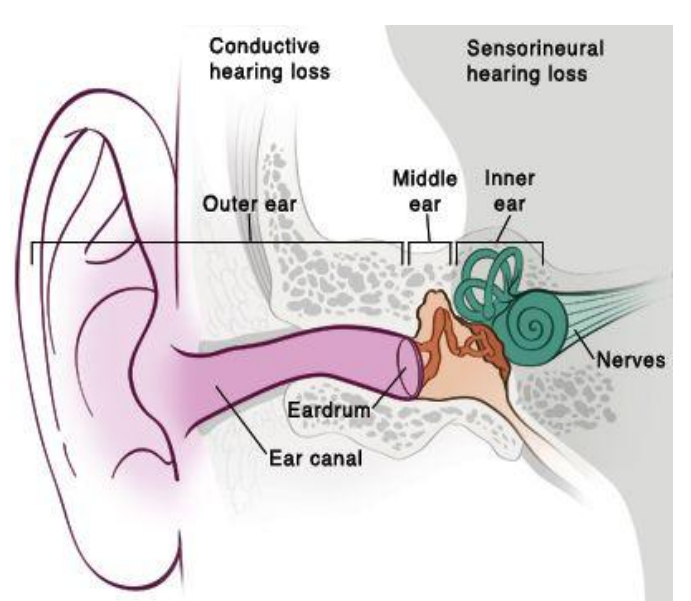

Fig. 3: Sensorineural hearing loss in the ear

\section{Results}

The functional impairment in hearing in the two groups was assessed. The hearing threshold in the better ear of the patient was taken to assess the degree of hearing loss in that patient.

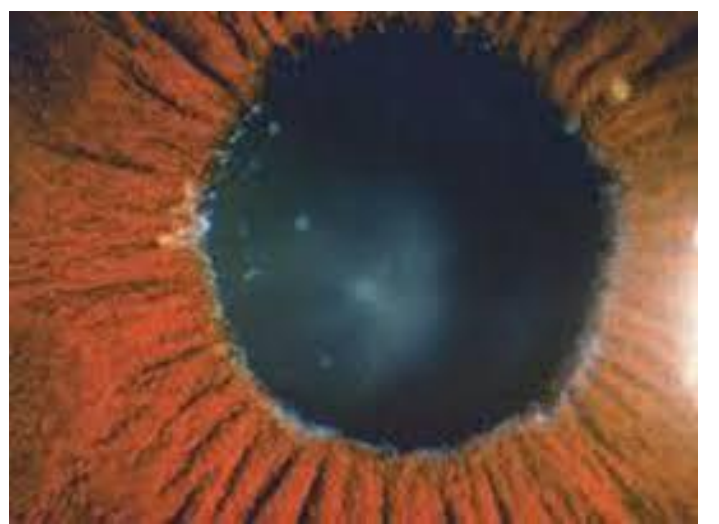

Fig. 1: Dandruff like flaky material on the pupillary margin 


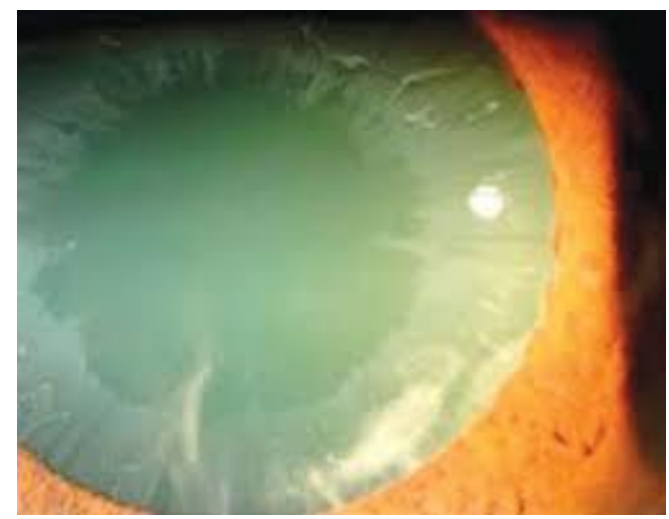

Fig 2: Pseudoexfoliative material on the anterior lens capsule

Table 2: Hearing threshold in the better ear in patients with and without psuedoexfoliation

\begin{tabular}{|l|c|c|c|c|}
\hline \multirow{2}{*}{$\begin{array}{l}\text { Pure tone average in the better } \\
\text { ear }\end{array}$} & \multicolumn{3}{|l|}{ Pseudoexfoliation } \\
\cline { 2 - 5 } & \multicolumn{2}{|c|}{ Present } & \multicolumn{2}{c|}{ Absent } \\
\cline { 2 - 5 } & $\mathrm{N}$ & $\%$ & $\mathrm{~N}$ & $\%$ \\
\hline$<=25$ (Not significant) & 18 & 40.9 & 25 & 56.8 \\
\hline $26-40$ (Mild) & 23 & 52.3 & 13 & 29.5 \\
\hline $41-55$ (Moderate) & 3 & 6.8 & 4 & 9.1 \\
\hline $56-70$ (Moderately Severe) & 0 & 0.0 & 2 & 4.5 \\
\hline Total & 44 & 100.0 & 44 & 100.0 \\
\hline$\chi^{2}=6.060$ & $\mathrm{df}=3$ & $\mathrm{p}=0.109$
\end{tabular}

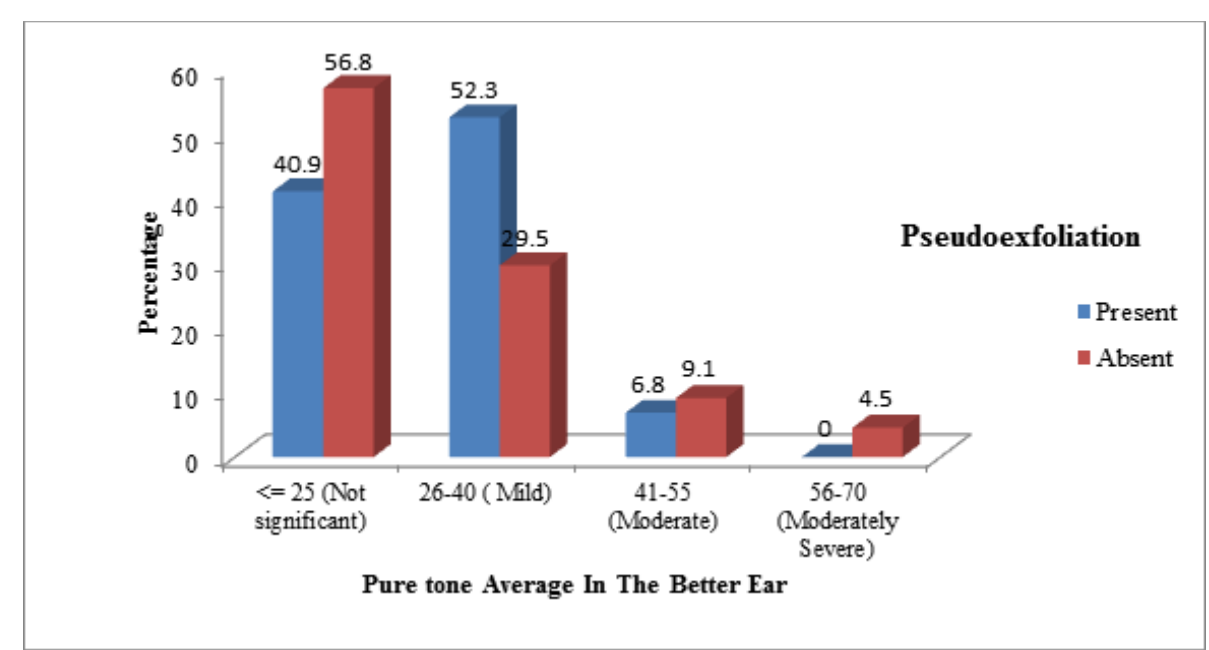

Fig. 4: Mean hearing threshold in the better ear in patients with and without pseudoexfoliation

From the table, it is evident that majority of the patients with pseudoexfoliation syndrome have mild hearing loss whereas in the group without pseudoexfoliation, majority had no hearing loss.

\section{Discussion}

Some of the initial studies like that done by Cahill et $\mathrm{al}^{4}$ compared the hearing thresholds of study subjects with the ISO 7029 median AAHL (Age Associated Hearing Loss) values to conclude if the patients had sensorineural hearing loss or not. The ISO 7029 values were calculated for Caucasian population and hence studies on Indian subjects cannot employ the same method. In the study conducted by Cahill et al,

$73.7 \%$ of the ears studied had sensorineural hearing loss $(n=69)$. The mean age of study subjects was more than 75 years. ${ }^{12}$ In the study conducted by Shaban et al, $87 \%$ had hearing thresholds higher than the ISO7029 standards $(\mathrm{n}=41){ }^{6}$

According to Shaban et al, of 41 patients studied 72 ears of 36 patients $(87 \%)$ had a higher hearing threshold level (HTL) at 1, 2, $3 \mathrm{kHz}(\mathrm{HTL} 1,2,3)$ than the ISO 7029 median AAHL (Age Associated Hearing Loss) 1, 2, 3 which included (44 ears) of 22 patients in 
the male group (87\%) and (28 ears) of 14 patients in the female group $(82 \%) .{ }^{15}$

In a study conducted by Turacli et al, in the group with psuedoexfoliation, $66.7 \%$ had hearing loss at various levels $(\mathrm{n}=102)$. In the group without psuedoexfoliation, $61.4 \%$ had no hearing loss, and $38.6 \%$ had hearing loss. The difference between the two groups is statistically significant. ${ }^{14}$

In the study done by Sameena Kokab et al, $90 \%$ in the group $(\mathrm{n}=60)$ with pseudo exfoliation had sensorineural hearing loss in one or both ears compared to $61.6 \%$ in the group without pseudoexfoliation $(n=60)$. The difference was statistically significant. ${ }^{7}$ This study was done in India but hearing thresholds were compared with ISO7029 standards to assess sensorineural hearing loss.

In the study conducted by Ozturk et al, $79.4 \%$ patients with pseudo exfoliation had sensorineural hearing loss while $26.3 \%$ of the subjects without pseudo exfoliation had sensorineural hearing loss $(n=63)$. The difference in the proportion of sensorineural hearing loss between the two groups was statistically significant. Presence of hearing loss was accepted when the average hearing threshold was higher than $25 \mathrm{~dB} .{ }^{5}$

In our study, hearing threshold in the better ear is used to determine if there is impairment or not. It was found that though an increased number of patients with pseudoexfoliation had hearing impairment (59.1\%) when compared to those without psuedoexfoliation (43.2\%), though the difference is not statistically significant. The limitation of the study is that presbyacusis and high frequency hearing loss has not been taken into account.

\section{Conclusion}

There is an increased incidence of hearing impairment in pseudoexfoliation syndrome though not statistically significant.

\section{References}

1. Krishnadas R, Nirmalan PK, Ramakrishnan R, Thulasiraj RD, Katz J, Tielsch JM, Friedman DS, Robin AL. Pseudoexfoliation in a rural population of southern India: the Aravind Comprehensive Eye Survey. Am J Ophthalmol. 2003 Jun;135(6):830-837.

2. Thomas R, Nirmalan PK, Krishnaiah S. Pseudoexfoliation in southern India: the Andhra Pradesh Eye Disease Study. Invest Ophthalmol Vis Sci. 2005 Apr;46(4):1170-6.

3. Arvind H, Raju P, Paul PG, Baskaran M, Ramesh SV, George RJ, McCarty C, Vijaya L. Pseudoexfoliation in South India. Br J Ophthalmol. 2003 Nov;87(11):1321-3.

4. Cahill M, Early A, Stack S, Blayney AW, Eustace P. Pseudoexfoliation and sensorineural hearing loss. Eye 2002;16:261-266.

5. Ozturk F, Kurt E, Inan UU, Derekoy S, Ermis SS, Asagidag A, Aktepe F, Şahin Ö. Is pseudoexfoliation associated with sensorineural hearing loss? Neurosciences 2008;13:61-64.
6. Shaban RI, Asfour WM. Ocular pseudoexfoliation associated with hearing loss. Saudi Med J 2004; 25(9):1254-1257.

7. Sameena Kokab, Jyothi Chavadaki, S. Neelkant, Sreekantha. The study of sensorineural hearing loss in pseudoexfoliation syndrome. Indian Journal of Public Health Research and Development 2013;4(3): 287-290

8. Lim DJ. Functional structure of the organ of Corti: a review. Hear Res 1986;22:117-146.

9. Larsen WJ. Developmentof the head, the neck, the eyes and ears. Essentials of embryology. New York: Churchill Livingstone, 1998:229-72.

10. Mitchell P, Wang JJ, Smith W. Association of pseudoexfoliation syndrome with increased vascular risk. Am J Ophthalmol 1997;124:685-687.

11. Naumann GO, Schlötzer-Schrehardt U. Keratopathy in pseudoexfoliation syndrome as a cause of corneal endothelial decompensation: a clinicopathologic study. Ophthalmology 2000;107(6):1111-24.

12. Turacli ME, Ozdemir FA, Tekeli O. Sensorineural hearing loss in pseudoexfoliation. Can J Ophthalmol 2007;42(1):56-59.

13. Shaban RI, Asfour WM. Ocular pseudoexfoliation associated with hearing loss. Saudi Med J 2004;25(9):1254-1257.

14. Sameena Kokab, Jyothi Chavadaki, S. Neelkant, Sreekantha. The study of sensorineural hearing loss in psuedoexfoliation syndrome. Indian Journal of Public Health Research and Development 2013;4(3):287-290.

15. Lindberg JG. Kliniska undersokningar over depigmenteringen av pupillarranden och genomlesbarheten av iris vid fall av aldersstrarr samt I normal ogon hos gamla personer [thesis]. Helsinki, Finland, Helsinki University, 1917.

16. Kanski JJ. Clinical Ophthalmology. A systematic approach. Oxford (UK): Butterworth Heinemann;1999. p. 217-219.

17. American Academy of Ophthalmology. Basic and Clinical Science course LEO 1998-1999;10:72-74.

18. Thorleifsson G, Magnusson KP, Sulem P, et al. Common sequence variants in the LOXL1 gene confer susceptibility to exfoliation glaucoma. Science. 2007;317(5843):1397-1400.

19. Liu X, Zhao Y, Gao J, et al. Elastic fibre homeostasis requires lysyl oxidase-like 1 protein. Nat Genet.2004;36(2):178-182.

20. Roth M, Epstein DL. Psuedoexfoliation Am J Ophthalmol 1980;89:477.

21. Kozart DM, Yanoff M. Intraocular pressure status in 100 consecutive patients with psuedoexfoliation Ophthalmology 1982;89:214.

22. Crittendon JJ, Shields MB. Psuedoexfoliation in the southeastern United States. II. Characteristics of patient population and clinical courses. Acta Ophthalmol 1988; 66 (Suppl 184):103.

23. Shields MB. Textbook of Glaucoma. 6th ed. Lippincott Williams \& Wilkins; 2011;248-261.

24. Ritch R, Schlötzer-Schrehardt U. Exfoliation syndrome. Surv Ophthalmol 2001;45:265.

25. Miyake K, Matsuda M, Inaba M.Corneal endothelial changes in exfoliation syndrome. Am J Opthalmol.1989;108(1):49-52.

26. Naumann GOH, Schlötzer-Schrehardt U.Keratopathy in exfoliation syndrome as a cause of corneal endothelial decompensation: a clinicopathologic study. Ophthalmology. 2000;107(6):1111-1124. 
27. Naumann GOH, Schlötzer-Schrehardt U.Corneal endotheliopathy of exfoliation syndrome(letter). Arch Ophthalmol.1994;112:297.

28. Layden WE, Shaffer RN. Exfoliation syndrome. Am J Ophthalmol.1974;78(5):835-841.

29. Sampaolesi R.Neue Untersuchungen uber das PseudoKapselhautchen-Glaucom (Glaucoma Capsulare)[in German] Ber Deutsch Ophthal Ges.1959;62:177-183.

30. Wishart PK, Spaeth GL, Poryzees EM. Anterior chamber angle in the exfoliation syndrome. $\mathrm{Br} \mathrm{J}$ Ophthalmol.1985;69(2):103-107.

31. Lindblom B, Thornburn W. Functional damage at diagnosis of primary open angle glaucoma. Acta Ophthalmol.1984;62(2):223-229.

32. Futa R, Shimizu T, Furuyoshi N, et al. Clinical features of capsular glaucoma in comparison with primary open angle glaucoma in Japan. Acta Ophthalmol. 1992;70(2):214-219.

33. Olivius E, Thornburn W. Prognosis of glaucoma simplex and glaucoma capsulare. A comparative study. Acta Ophthalmol.1978;56(6):921-934.

34. Tezel G, Tezel TH. The comparative analysis of optic disc damage in exfoliative glaucoma. Acta Ophthalmol.1993;71(6):744-750.

35. Schlötzer-Schrehardt U, Naumann GOH. Ocular and systemic pseudoexfoliation syndrome. Am J Ophthal.2006;141(5):921-937

36. Radda TM, Klemen UM. True idiopathic exfoliation [in German]. Klin Monbl Augenheilkd.1982; 181(4):276-277.

37. Brodrick JD, Tate GW Jr. Capsular delamination (true exfoliation) of the lens. Report of a case. Arch Ophthalmol.1979;97(9):1693-1698.

38. Cashwell LF Jr, Holleman IL, Weaver RG,et al. Idiopathic true exfoliation of the lens capsule. Ophthalmology.1989;96(3):348-351.

39. Tsukahara S, Matsuo T. Secondary glaucoma accompanied with primary familial amyloidosis. Ophthalmologica.1977;175(5):250-262.

40. Schwartz MF, Green WR, Michels RG, et al. An unusual case of ocular involvement in primary systemic nonfamilial amyloidosis. Ophthalmology. 1982;89(4):394-401.

41. PL Dhingra, Shruti Dhingra. Diseases of ear, nose and throat and head and neck surgery. $6^{\text {th }}$ ed. Elsevier 2014;32-38. 